\title{
The Effect of Application Requirement Availability on Cloud Computing Adoption in Jordan
}

\author{
Salwa Alsamrai ${ }^{1}$, Omar Sabri ${ }^{2}$, Amaal Al-Amawi ${ }^{3}$ \\ Isra University, Administrative Sciences and Finance, Management Information Systems, Amman, Jordan ${ }^{1}$ \\ Jazan University, Business Administration, Management Information System, Jazan, Saudia Arabia ${ }^{2}$ \\ Isra University, Administrative Sciences and Finance, Management Information Systems, Amman, Jordan ${ }^{3}$
}

\begin{abstract}
The purpose of this study is to evaluate the effect of application requirements availability on adopting cloud computing applications in several government institutions in Jordan. To go deeper in cognition of the phenomena under investigation, survey method was used to collect data, and for respondent persuade all the inquiries asked in this study were coordinated in Arabic language. We applied (Cronbach's Alpha) to analyze the validity and reliability of the survey which resulted in acceptable stability for the purposes of conducting research. The research sample was represented by all the workers of the system implementation in different government institutions, where the total sample size was 50 employees. The statistical analysis showed that there was a significant and positive influence of the availability of cloud computing technology requirements on the adoption of its application in the Jordanian institutions.
\end{abstract}

Keywords: Cloud Computing adoption; Government institutions; Survey; Jordan

\section{INTRODUCTION}

Many researchers defined the cloud computing as a set of less cost, minimum resources, maximum speed and less hardware, interfaces, networks, storage, and services that time. The most popular governments that implemented allow the prompt delivery of software and services over and established cloud system are Japan, Singapore, USA, the Internet upon user demand. It provides infrastructure Finland, Korea, and UK. [4, 6]. Each of the previous and services and programs through a network that offers government is focusing on cloud computing as the attractive advantages for organizations, including its solution for the efficiency of the electronic government, ability to reduce ICT costs through centralized business innovation, ICT efficiency, and cost reduction infrastructure, which is working to install more than one [5,6]. For many years, governments began to move operating system (Windows - Mac - Linux - others) in a towards online and provide their services, and build a virtual environment within the current operating system to strong relationship with citizens to interact directly with experience the system as a program could be viewed at them. The value of governments to move on line is to any time [1].

There are many definitions of cloud computing in the literature but the most one was defined by the National Institute Of Standard And Technology (NIST) of America defined Cloud Computing as the following: "Cloud computing is a model for enabling convenient, on demand network access to a shared pool of configurable computing resources (e.g., networks, servers, storage, applications, and services) that can be rapidly provisioned and released with minimal management effort or service provider interaction." [2].

Clouds are used to save organizational resources, because the traditional organizations did not use the entire functionality of technology such as network capacity, storage capacity, server's functionality and power electricity. So organizations can reduce the cost consuming on equipments and reduce electrical power consuming [3]. Not only organizations can get benefits from cloud technology system, but also governments expect public services should be available to people with develop the efficiency and effectiveness, and transparency between the government and its agencies, between government and its citizen, and between government and the private sector, i.e E-government $[5,6,7]$.

Many governments in the Middle East like Saudi Arabia, UAE, and Qatar, have realized the importance of Information technology and cloud computing in enhancing and maintaining their economies. These governments are committed to take their services online to develop their infrastructure and services to the public [8].

The cloud computing project was launched officially in Jordan in 2013 to provide centralized and secured infrastructure for government institutions. Recently, the Jordanian government has announced that a great amount of support will be spent over cloud computing infrastructure. In this research, we are going to probe the effect of the availability of application kits (Infrastructure, specialist staff, awareness of system adoption, and protection means) on adopting cloud computing in government institutions in Jordan. 
The paper will be organized as the following: Background in information technology, which means hiring more including Research importance, problem statement, personnel in sales finance, production, marketing, and etc... Hypotheses, and Research goals are presented in Section However, it is noticeable that this technique needs 2. The most recent and related work is presented in infrastructure, programs, service provider, high level of Section 3. In Section 4 we present and discuss the system security, and government security legislation to proposed model. Finally, a number of conclusions are ensure the preservation of the vast amount of data security. drawn and recommendations for future work are pointed- Moreover, the technique requires the availability of out.

\section{BACKGROUND}

There are three categories of cloud computing technologies services as (NIST) characterized [2, 14]:

- Infrastructure as a Service (IaaS): it is the daily use of the software with a cost as per use.

- Platform as a Service (PaaS): is about delivering services without managing the infrastructure through providing standardization in operating system, database, and query.

- Software as a Service (SaaS): implies leasing computing capacity and equipment (e.g. data centers, servers, storage, networking or web hosting) conveyed when required.

- Cloud computing could be also divided into four models in terms of service oriented architecture into [6, 9, 14]:

- Public Cloud: which supports on demand computing resources provided over the Internet

- Private Cloud: that private networks exclusively used by everyone in the organization.

- Community Cloud: provides services to a community within organization. Members of community can access data on community cloud.

- Hybrid Cloud: it is a combination of private, public and community cloud.

- In our research we will focus on the IaaS, and PaaS technology based on public and private cloud architecture in some Jordanian government institutions.

\section{A. Research importance}

The results of a study conducted by IDC Research Foundation commissioned by Microsoft Corporation showed new opportunities for business and communities as a result of the use of Cloud Computing technologies [10]. The study confirmed that it is expected by the end of 2015 more than 14 million new jobs would appear as a direct result of the investment in cloud computing technologies.

This research comes to emphasize the remarkable difference achieved by cloud computing technologies in the field of business in terms of raising the level of productivity, reducing costs and drawing attention of IT teams to focus on the most important business issues, which in turn will lead to the recovery of the global economy.

\section{B. Problem statement}

It is known that the cloud computer technology releases organizations from antique systems and allow companies to invest in more creative techniques. The efficiency and performance levels gained from cloud computing techniques are reflected on innovation in general not only addition, providing awareness by the government and the companies of the importance of the adoption of this technology is important for system adoption. Hence the importance of the problem of the research study of the availability of these elements that can be considered as the catalyst to adopt these technologies in private companies or governments in the Arab world, especially in Jordan which began to adopt this technology to work on their application because of the benefits it brings. The researchers will try through this research to identify the problems and difficulties that stand as obstacle towards adopting or applying this technology.

\section{Research Goals}

We can identify research targets as the following:

- Provide a conceptual framework about the cloud computing system, and review the most important previous studies on this topic.

- Determine the correlation between the availability of cloud computing technology application requirements and the adoption of its application in the Jordanian government institutions.

- Measuring the influential relationship between the availability of awareness of the importance of cloud computing technology and the adoption of its application in the Jordanian government institutions.

- Determine the influence of the relationship between the necessary infrastructure to provide application of cloud computing technology and the adoption of its application in the Jordanian government institutions.

- Identify the influence of the relationship between the availability of specialist staff to the application of cloud computing technology and the adoption of its application in the Jordanian government institutions.

- Determine the correlation between the availability of protection means for the application of cloud computing technology and the adoption of its application in the Jordanian government institutions.

\section{LITERATURE REVIEW AND RESEARCH HYPOTHESES}

Few papers discussed the benefits of cloud computing on government, but many on business. One reason for that relate to its obvious newness and underdevelopment of the market for cloud services. The most suitable cloud category for government is private cloud since it is similar to organization network where it meets data classification, services, and security $[3,14,8]$.

Nikolova [3] discussed the benefits and barriers for government from cloud computing implementation. The author concluded with changing requirements in 
legislation and security decisions for defining the Sub-first hypothesis H1: "Awareness of cloud computing precedence and privileges for data access. In terms of importance will negatively affect on cloud computing benefits as mentioned in Nikolova [3], cloud computing adoption."

enhances citizen services and allows government to offer Sub-second hypothesis H2: "Infrastructure will negatively its data on portals also due the effective communication affect on cloud computing adoption."

multiple users can use the data stored in the cloud. There Sub-third hypothesis H3: "Specialist staff will negatively is no need for new infrastructure; instead government will affect on cloud computing."

only pay for the required IT resources. Moreover, Sub-fourth hypothesis H4: "Protection means for cloud government gains flexibility of adjusting cloud-based computing application will negatively affect on cloud resources to meet real time applications and develop computing adoption."

operational efficiencies. Finally, since the government has hosted services, software, and datasets, it can concentrate on its main business and services. In terms of barriers, trust and security are considered as the basic problem in government agencies, performance of public services, environment integration difficulties with the existing work environment, and IT outsourcing [11].

Shoshtari[12] conducted theoretical and empirical methods to study the adoption of cloud computing technology in Iran. They investigated set of factors to assess the cloud readiness in the country through highlighting the strength and weakness points and proposed a road map framework to adopt cloud computing in Iran. The factors in the framework were classified into three categories: 1) Government planning including Awareness of Policy Makers, Legal and Regulatory Issues, Interoperability Standards, and Promoting and Monitoring. 2) ICT infrastructure including Broadband, Data Centre, Support, and Mobile Service. 3) Organizations' responsibilities including Agenda Setting Phase, Matching Phase, Clarifying Phase, Restructuring Phase, and Routine Phase. Kumar et al [13] Proposed an E-Governance model framework which utilizes the potential of cloud computing. They suggested three tier cloud architecture for Indian scenario, and used SWOT analysis to investigate the pros and cons of the proposed solution.

\section{A. Hypotheses}

Based on the previous studies, it can be concluded that this technique needs infrastructure, programs, service provider, high level of system security, and government security legislation to ensure the preservation of the vast amount of data security. Moreover, the technique requires the availability of specialist staff to use and implement it successfully. Also providing awareness by the government and the companies of the importance of the adoption of this technology is important for system adoption. Hence we developed the main hypothesis and its sub hypothesis based on the following factors: (Awareness of cloud computing importance; Infrastructure such as tools, servers, networks, communications, programs, service provider.etc; Specialist staff in terms of technicians or managers who know how to deal with this new technology; and Protection means in terms of protecting data from loss, penetration, modification, stealing, exploitation.etc). The study hypothesis with its factors is depicted in Figure. 1

The main hypothesis H0: "Cloud Computing Technological requirements will negatively affect on cloud computing adoption". It is subdivided into several subhypotheses:

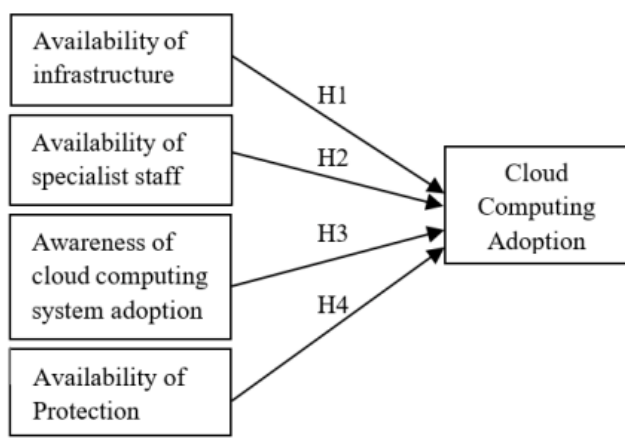

Figure. 1 The research model

\section{RESEARCH METHODOLOGY}

The descriptive and analytical approach is used based on data collection via questionnaire. The questionnaire was analyzed statistically to test the validity of the research hypotheses, as well as the reliance on the scientific journals, web sites, and the most previous studies to construct the theoretical framework of the research.

The authors used SPSS to extract the averages and standard deviation for the research variables. Also they used Cronbach's Alpha to measure the stability of the questionnaire, analyze simple and multiple regressions, and measure the effect of independent variables on dependent variables. Finally, they used Wise Regression testing to find the most effective variable.

A. Research tool and variables:

The variables adopted by researchers are: i) Independent variables: the availability of cloud computing technology application requirements (provide awareness of the importance of application, provide the necessary infrastructure, provide specialist staff, and provide protection means for the application). ii) Dependent variable (the adoption of cloud computing application in Jordanian government institution). The variables were measured using a five-point Likert scale as follows: (5) strongly agree (4) agree (3) neutral (2) do not agree (1) strongly disagree.

B. Analyzing the results of validity and reliability: The questionnaire was reviewed by specialist professors in Jordanian universities, and presented to those responsible for the preparation and implementation of the system at the Ministry of Communications and Information Technology of Jordan. Their observations were taken, and some paragraphs were rewritten. The coefficient reliability (Cronbach's Alpha) was applied on the variables and 
resulted in acceptable stability for the purposes of conducting research. As shown in table 1 the reliability

Table 1 Persistence of variables questionnaire transactions

\begin{tabular}{|l|c|}
\hline \multicolumn{1}{|c|}{ Variable name } & Reliability Coefficient \\
\hline Availability of infrastructure & 61 \\
\hline Availability of specialist staff & 78.4 \\
\hline $\begin{array}{l}\text { Awareness of cloud computing } \\
\text { system adoption }\end{array}$ & 61.6 \\
\hline $\begin{array}{l}\text { Availability of Protection } \\
\text { Means }\end{array}$ & 76.5 \\
\hline System application adoption & 85.7 \\
\hline
\end{tabular}

C. Research Sample and Population.

The cloud computing project was implemented officially in Jordan in 2013 to provide centralized and secured infrastructure for government institutions.

Table 2 personal and functional information of research sample members

\begin{tabular}{|c|c|c|c|}
\hline variables & intervals & Freq. & percent \\
\hline \multirow[t]{2}{*}{ Gender } & male & 36 & 72 \\
\hline & female & 14 & 28 \\
\hline \multirow[t]{4}{*}{ age } & $30-25$ & 14 & 28 \\
\hline & $35-31$ & 14 & 28 \\
\hline & $40-36$ & 14 & 28 \\
\hline & 41 and above & 8 & 16 \\
\hline \multirow[t]{4}{*}{ Experience } & Less than 5 years & 8 & 16 \\
\hline & $10-6$ & 20 & 40 \\
\hline & $15-11$ & 12 & 24 \\
\hline & $\begin{array}{l}\text { More than } 16 \\
\text { years }\end{array}$ & 10 & 20 \\
\hline \multirow[t]{4}{*}{ Education } & Computer Science & 14 & 28 \\
\hline & $\begin{array}{l}\text { Computer } \\
\text { Information } \\
\text { Systems }\end{array}$ & 4 & 8 \\
\hline & $\begin{array}{l}\text { Software } \\
\text { engineering }\end{array}$ & 10 & 20 \\
\hline & others & 22 & 44 \\
\hline \multirow[t]{4}{*}{ Job title } & employee & 26 & 52 \\
\hline & supervisor & 8 & 16 \\
\hline & programmer & 14 & 28 \\
\hline & Manager & 2 & 4 \\
\hline \multirow{3}{*}{$\begin{array}{l}\text { The number } \\
\text { of courses in } \\
\text { the field of } \\
\text { computers } \\
\text { and software } \\
\text { cloud } \\
\text { computing } \\
\text { system } \\
\text { application }\end{array}$} & $2-1$ & 36 & 72 \\
\hline & $4-3$ & 4 & 8 \\
\hline & $\begin{array}{l}\text { More than } 5 \\
\text { courses }\end{array}$ & 8 & 16 \\
\hline \multirow{3}{*}{$\begin{array}{l}\text { Duration of } \\
\text { system usage }\end{array}$} & Less than a year & 10 & 20 \\
\hline & 1-2 year & 12 & 24 \\
\hline & More than 3 years & 28 & 56 \\
\hline
\end{tabular}

for all variables are high where reached up to 89.2. The research population is the institutions that applied cloud computing system, while the research sample is represented by all the workers of the system implementation in the institutions mentioned above, where the total sample size (50) employees. Table 2. The results of the personal and functional characteristics indicate that all involved employees have experience and scientific qualifications in the field of computer and have training in their specialties. Most of the institutions have been applying the system since at least 3 years ago.

\section{DISCUSSION}

The results of the personal and functional characteristics indicate that all involved employees have experience and scientific qualifications in the field of computer and have been training in their specialties. Most of the institutions have been applying the system since at least 3 years ago. $96 \%$ of the employees are using the infrastructure as a cloud computing service, and $60 \%$ of them are using the system for software services. Most of the employees (72\%) are using cloud computing service in the field of achieving government services. The most risks that may face cloud computing application as indicated by the research sample are arranged in descending order as the following: data theft $84 \%$, data loss $84 \%$, computing services abuse $80 \%$, exploiting service $56 \%$, and technological vulnerabilities either in the institution itself or due ISP. The average score of system infrastructure availability is 4.156 and standard deviation of 0.412 this result emphasizes the necessity of infrastructure requirement to adopt cloud computing system. The average score of specialist staff availability reaches 3.794 with standard deviation of 0.581 which indicates to the ability of adopting the system. The awareness of system adoption got the average score of 3.577 and standard deviation of 0.554 . However, the phrase that did not get the agreement is "During my university study I got to know the concept of cloud computing and its uses through some subjects". This goes to the outdated subjects that do not cope with development. There is a general agreement about the availability of protection means with average score 3.504 and standard deviation of 0.398 . However, the employees declare that their institution is not facing difficulty in data protection in the cloud, depending on the traditional security practices. There is a general agreement about the necessity of cloud computing adoption with an average score (4.103) and standard deviation (0.383). The mean of each system requirement variables in terms of infrastructure, specialist staff, protection means, and awareness of system adoption is shown in table 3.

Table 3 research variables sample respondents' means

\begin{tabular}{|l|c|}
\hline \multicolumn{1}{|c|}{ variables } & Mean \\
\hline System application adoption & 0.65 \\
\hline Availability of infrastructure & 0.37 \\
\hline Availability of specialist staff & 0.35 \\
\hline Availability of Protection Means & 0.49 \\
\hline $\begin{array}{l}\text { Awareness of cloud computing } \\
\text { system adoption }\end{array}$ & 0.43 \\
\hline
\end{tabular}


International Advanced Research Journal in Science, Engineering and Technology

Vol. 3, Issue 6, June 2016

Table 4 multiple regression of the relationship between requirements availability and cloud computing adoption

\begin{tabular}{|l|l|l|l|l|l|l|l|l|}
\hline $\begin{array}{c}\text { Variance } \\
\text { source }\end{array}$ & $\begin{array}{c}\text { Deviation } \\
\text { squared }\end{array}$ & $\begin{array}{c}\text { Degrees } \\
\text { of } \\
\text { Freedom }\end{array}$ & Avg. & $\begin{array}{c}\text { Value } \\
-\mathrm{F}\end{array}$ & Sig. & $\mathrm{R}$ & $\mathrm{R}^{2}$ & $\begin{array}{c}\text { Variance } \\
\text { in R }\end{array}$ \\
\hline regression & 3.001 & 4 & 0.75 & 8.04 & 0.000 & 0.65 & 0.42 & 0.37 \\
\hline error & 4.199 & 45 & 0.931 & & & & & \\
\hline Total & 7.2 & 49 & & & & & & \\
\hline
\end{tabular}

Table 5 simple regression for independent variables

\begin{tabular}{|l|l|l|l|l|l|l|}
\hline $\begin{array}{l}\text { Independent } \\
\text { variable }\end{array}$ & $\begin{array}{l}\text { Dependent } \\
\text { variables }\end{array}$ & $\begin{array}{l}\mathrm{T} \\
\text { value }\end{array}$ & $\mathrm{Sig}$ & $\begin{array}{l}\mathrm{R} \\
\text { value }\end{array}$ & $\begin{array}{l}\mathrm{R}^{2} \\
\text { value }\end{array}$ & $\begin{array}{l}\text { Variance } \\
\text { in } \mathrm{R}^{2}\end{array}$ \\
\hline \multirow{3}{*}{$\begin{array}{l}\text { cloud computing } \\
\text { adoption }\end{array}$} & Infrastructure & 2.77 & 0.008 & 0.37 & 0.13 & 0.12 \\
\cline { 2 - 7 } & Specialist & 2.59 & 0.013 & 0.35 & 0.12 & 10.4 \\
\cline { 2 - 7 } & Awareness & 3.33 & 0.002 & 0.43 & 0.18 & 0.17 \\
\cline { 2 - 7 } & Protection Means & 3.91 & 0.000 & 0.49 & 0.24 & 0.22 \\
\hline
\end{tabular}

Table 6 sequential regression for research hypothesis

\begin{tabular}{|l|l|l|l|l|l|}
\hline \multicolumn{1}{|c|}{ Independent variable } & $\mathrm{R}$ & $\mathrm{R}^{2}$ & Variance in $\mathrm{R}^{2}$ & $\mathrm{~F}$ & $\begin{array}{c}\text { Significant } \\
\text { level }\end{array}$ \\
\hline Security Variable & 0.492 & 0.242 & 0.226 & 15.29 & 0.000 \\
\hline (Infrastructure and security ) variables & 0.596 & 0.355 & 0.328 & 12.937 & 0.000 \\
\hline $\begin{array}{l}\text { (Infrastructure, Protection Means and } \\
\text { awareness ) variables }\end{array}$ & 0.64 & 0.410 & 0.371 & 10.65 & 0.000 \\
\hline
\end{tabular}

The Multiple regression analysis related to test the main importance of constituent variables of system hypothesis rejected the null hypothesis and accepted the requirements variable varies in its importance which alternative hypothesis. This means that the availability of confirms all the previous tests.

cloud computing technology application kits contribute to the success of the adoption of cloud computing system. That is illustrated by the value of $(\mathrm{R} 2=0.42)$ which shows the susceptibility explanatory for this variable.

The simple regression analysis also rejected the sub hypothesis of the requirements, namely, (infrastructure, specialist staff, awareness of system adoption, and availability of protection means), where there is no relationship between them and system adoption variable. The alternative hypothesis is accepted which refers to the existence of the influence of a relationship with a significant difference between all of these variables and system adoption. The degree of the relative importance towards explaining each independent variable was determined in descending order as the following:

"the availability of protection means, " got the highest rate of (0.24) by a factor of correlation of (0.49), followed by " Awareness of system adoption" a rate of (0.18), correlation coefficient ( 0.43$)$, followed by "availability of infrastructure" rate of (0.13), correlation coefficient (0.37), and finally "availability of specialist staff" at a rate of $(0.12)$ by a factor of correlation $(0.35)$.

The results of sequential regression analysis came to confirm the previous results where the lowest influencing sub variables on system adoption were excluded, then the most influencing variables "provide protection" infrastructure "and" provide awareness "together, reaching a correlation coefficient (0.064) and the coefficient of determination or influential force $(0.41)$, while " provide specialist staff " was excluded where its impact was the lowest. These are logical results came to prove that the

\section{CONCLUSION}

This paper investigates the influence of requirements availability towards adopting cloud computing in Jordan. The study is applied on employees worked in different government institutions: The Ministry of Environment, The Ministry of Justice, King Abdullah II Fund for Development, and Investment Promotion Board. The statistical results emphasize the significant influence of the requirements availability on cloud computing adoption.

The implications of the findings of this study indicate that: Employees are using the infrastructure as a cloud computing service more than using the system for software services.

The most risks that may face cloud computing application are data theft and data loss. A reasoning number of employees think that their institutions are not facing difficulty in data protection in the cloud, depending on the traditional security practices. Finally, a noticeable amount of employees think that they did not have solid background about this technology during their university studies due to the outdated subjects that do not cope with the technological development.

\section{RECOMMENDATIONS}

It is highly recommended that taking advantage of the theories and researches conducted in the areas of cloud computing to enhance the algorithms, methods and innovative strategies to store large data, and exploit this technique to find solutions towards providing resources 
and ensuring efficient service. As well as activating the role of governments, companies and electronic enterprises to take advantage of various types of cloud computing technology.

The need to increase efforts to convoy the evolution in the fields of computing and give more attention to matters of information security and the interaction of the computer, there will come a time where all the governments, institutions and corporate data become associated with cloud computing where all operating systems will turn into very large and high speed cloud systems.

In the scope of education, it is recommended harnessing cloud technology in the educational objectives service in several areas, including the integration between traditional and e-learning education and give some lectures or classes remotely.

Encourage research centers at universities to conduct scientific research to test the effectiveness of cloud computing. Encourage governments and Electronic Transactions to conduct scientific meetings and courses of the uses of cloud computing. The need to develop laws and regulations related to private cloud computing and the need to rehabilitate the judges to enable them to deal with cloud computing technology issues.

The need of teach cloud computing in information technology, and management information systems colleges as a compulsory material requirement. Intensify the training efforts for employees to be eligible for the application of this technique in institutions. It is important to conduct a study to evaluate the system after a long period of application to diagnose the strengths and weaknesses in the system application.

\section{REFERENCES}

[1] Bhatta, D. 2012. Revolution in Information Technology - Cloud Computing. Walailak J. Sci. \& Tech., 2012; 9(2) 107-113

[2] Mell, P., Grance, T." The NIST definition of cloud computing."NIST Special Publication 800-145. (2011). http://csrc.nist.gov/publications/nistpubs/800-145/SP800-145.pdf

[3] Nikolova, Mria "CLOUD COMPUTING IN GOVERNMENT. "// Proceedings of the International Conference on Information Techn;2012, p202

[4] Dutta, S., Geiger, T., \& Lanvin, B. "The global information technology report 2015. ICTs for inclusive growth.” Geneva: World Economic Forum. Retrieved from http://www3.weforum.org/docs/WEF_Global_IT_Report_2015.pdf

[5] Hashemi, S. Cloud Computing Technology For Egovernment Architecture. International Journal in Foundations of Computer Science \& Technology (IJFCST), Vol. 3, No.6, November 2013 DOI: 10.5121

[6] Hashemi, S., Monfaredi,K., and Masdari, M.2013. Using Cloud Computing for E-Government: Challenges and Benefits. World Academy of Science, Engineering and Technology. International Journal of Computer, Information, Systems and Control Engineering Vol:7 No:9, 2013

[7] Al-Rashedi. A. "E-Government Based on Cloud Computing and Service- Oriented Architecture" International Journal of Computer and Electrical Engineering, Vol. 6, No. 3, June 2014

[8] Naser N. ALMutairil \& Shebaib Fahad Thuwaini." Cloud Computing Uses for E-Government in the Middle East Region Opportunities and Challenges" International Journal of Business and Management Vol.10, No.4 Feb 2015

[9] Gong Zhang, Chiu, L, Ling Liu, "Adaptive Data Migration in Multi-tiered Storage Based Cloud Environment.”, IEEE software, p148 - 155, 2010.
[10] http://www.businessinsider.com/cloud-computing-could-create-14million-jobs-worldwide-by-2015-2012-3

[11] Henze, M.; Hermerschmidt, L. ; Kerpen, D.; Häußling, R. ;Rumpe, B.; Wehrle, K.., "A comprehensive approach to privacy in the cloud-based Internet of Things" Future generation computer systems, Volume 56 Issue C, P 701-718, March 2016.

[12] Shoshtari, M., \& Farid, S. " Cloud Computing Adoption in Developing Countries - A Tentative Framework Based on Experiences from Iran". Master, University of Borås. (2013MASI04) .

[13] Kumar, V., Mukerji, B., Irfan, B. and Ajax, P. " Factors for Successful e-Government Adoption: A Conceptual Framework." The Electronic Journal of e-Government, 5, 1, 63-77, 2007.

W. A. Jansen, "Cloud hooks: security and privacy issues in cloud computing NIST," in Proc. the 44th Hawaii International Conference on System Sciences, 2011. 